\title{
REPERCUSIONES TERRITORIALES DE LA POLÍTICA AGRARIA COMUNITARIA SOBRE LAS ESTRUCTURAS AGRARIAS DEL ALTO Y MEDIO VINALOPÓ (ALICANTE)
}

\author{
Antonio M. Rico Amorós
}

\section{RESUMEN}

La política de estructuras agrarias de la Unión Europea, sometida ahora a un hondo proceso de reflexión y reforma, ha propiciado en el Alto y Medio Vinalopó una serie de repercusiones estructurales, productivas, y espaciales. Las primas que regulan el arranque definitivo de superficies de viñedo, con más de 7.000 Has arrancadas hasta la actualidad constituyen su más relevante exponente, aunque no es el único ni mucho menos. Este trabajo persigue la identificación y evaluación de las líneas de ayuda comunitarias, estatales, y autonómicas, de efectos espaciales más relevantes, sometiendo los mismos a reflexión.

Palabras clave: política agraria comunitaria (P.A.C.), arranque de viñedo, explotaciones agrarias.

\section{ABSTRACT}

The agrarian structures policy of European Union, which is now submitted to a deep process of reflection and reform, has originated in the «Alto y Medio Vinalopó (Alicante)» some structural, productive and spatial repercussions. The bonuses which regulate the definitive pull up of vineyard surfaces, more of 7.000 has until now, constitute its more eminent exponent although it isn't the only far from it. This research pursues the identification and evaluation of the communitary, statal and autonomic assistance lines of more eminent spatial effects submitted to reflection. 
Key words: The Agrarian structures policy, pull up vineyard, agrarian explotations.

\section{Los efectos de la política de precios y mercados. Mecanismos de protección interna y externa}

Como es sabido los precios en el mercado agrícola único pueden oscilar entre un mínimo o suelo, que viene dado por los precios garantizados, y un máximo o techo, que es el precio indicativo. Administrativamente se fijan: el precio mínimo, que actúa de precio suelo, precio de garantía o precio de intervención para asegurar un nivel de retribución a los agricultores; y el precio máximo, precio techo, precio guía o precio indicativo, para que los consumidores no tengan que pagar más de ese nivel. Relativamente próximos a los precios guía, se fijan los precios de entrada - cuya diferencia con aquellos viene definida por los costes de transporte- con el objetivo fundamental de que las importaciones accedan al mercado comunitario a un nivel que no cree competencia para la producción interna; los productos exportados a la CEE a precios inferiores a los precios de entrada se gravan con una exacción variable o prélèvement con lo cual se nivela el precio del producto foráneo con el precio de entrada.

Las producciones más representativas del Alto y Medio Vinalopó quedan incluidas en las Organizaciones Comunes de Mercado siguientes:
Frutas y hortalizas
O.C.M. regulada por el Regl. 1.035/72
Vino
O.C.M. regulada por el Regl. 822/87
Olivar
O.C.M. regulada por el Regl. 136/66

En el ámbito de la organización común de mercados relativa a frutas y hortalizas, una de las más importantes para la Cuenca del Vinalopó el juego combinado del precio de base y de los precios de compra y de retirada conduce a las dos siguientes posibilidades:

- la autorización a las Organizaciones de Productores de Frutas y Hortalizas (O.P.F.H.) para que no pongan a la venta determinadas frutas y hortalizas producidas por sus asociados cuando los precios de mercado se sitúan al nivel de los precios de retirada, con el fin de que el mercado se recupere ante esta reducción de la oferta.

- declaración de si dicha recuperación no tiene lugar y el hundimiento de precios llega a alcanzar el nivel de precio de compra; en este caso las compras públicas realizadas por el organismo estatal de intervención alcanzan a la producción de cualquier agricultor, asociado o no a una O.P.F.H.

Las retiradas de producción realizadas por las O.P.F.H. y las compras públicas del organismo de intervención (S.E.N.P.A.) llevadas a cabo en las últimas campañas en el Vinalopó son las contenidas en el cuadro de la página siguiente. 


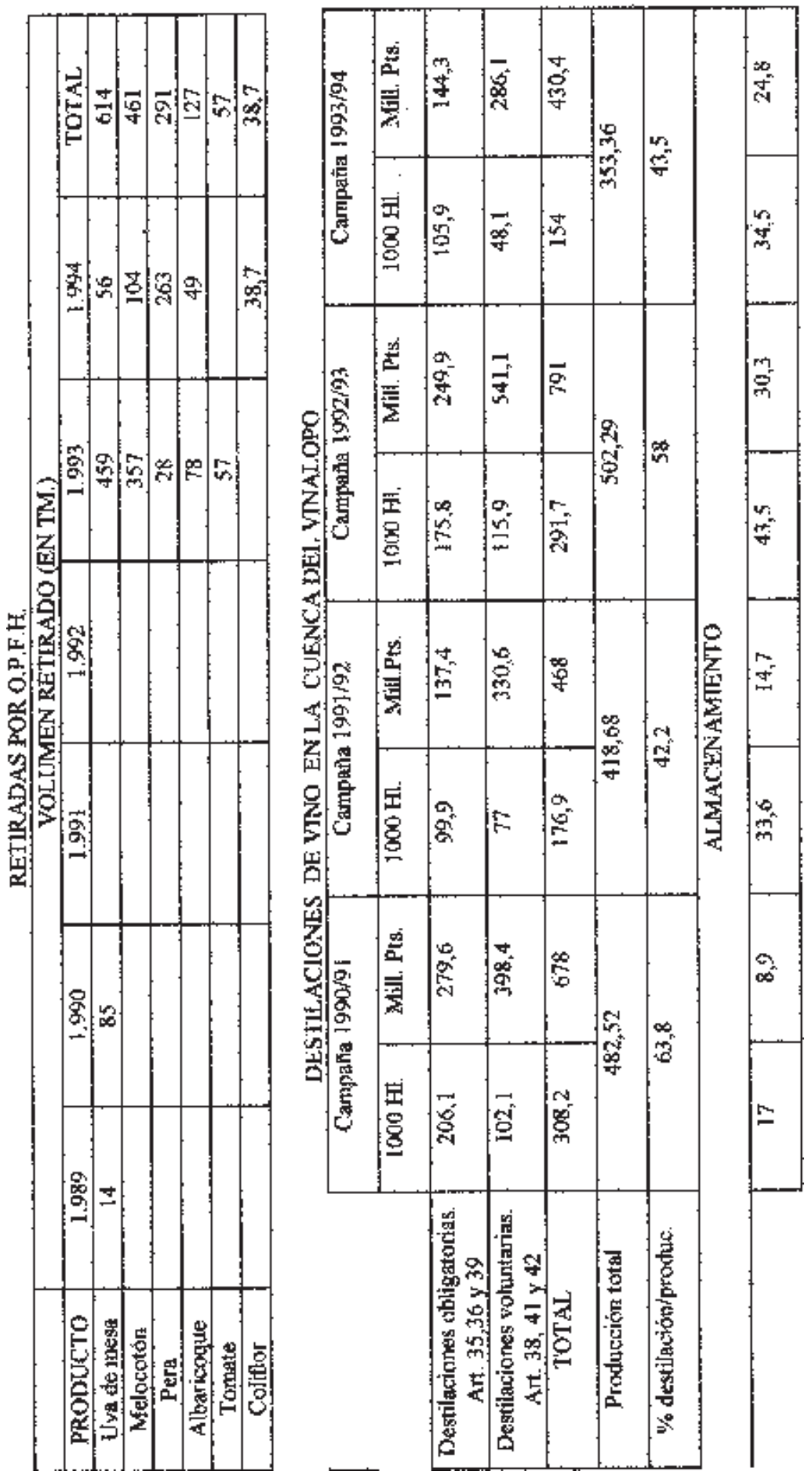


Mientras que estas intervenciones en el sector de frutas y hortalizas son coyunturales y vienen determinadas por la evolución del mercado, la situación es distinta en el sector vitivinícola, de tanta importancia en el Alto y Medio Vinalopó donde el balance entre disponibilidades y utilizaciones (consumo humano, exportación y utilización industrial) pone en evidencia la existencia de unos excedentes que son habitualmente superiores a las existencias almacenadas deseables, fijadas en el nivel necesario para satisfacer las necesidades de cuatro meses de campaña.

La intervención es permanente y aparte de los contratos de almacenamiento, utiliza fundamentalmente la práctica de la destilación pudiendo ser voluntaria, cuando el agricultor considera que tendrá dificultades para comercializar toda la cosecha, en cuyo caso percibe un precio igual al $65 \%$ del precio de orientación, o bien puede ser obligatoria cuando:

a) las disponibilidades observadas al comienzo de la campaña sobrepasan en más de cuatro meses las utilizaciones normales o

b) la producción es superior en más de un $9 \%$ a las utilizaciones normales o

c) la media ponderada de los precios representativos del mercado de todos los tipos de vinos de mesa es, al comienzo de la campaña, inferior al $82 \%$ del precio de orientación.

\section{Efectos de la política de estructuras (CEE) en la cuenca del Vinalopó de 1989/1991 a través del R.D. 808/87}

Como ya se ha apuntado la Reforma de la Política Agraria Común ha afectado también a aquellas líneas de ayuda que se destinaban de forma directa a la evolución de las estructuras agrarias, esto es, a la mejora de la eficacia de las explotaciones agrarias. Como es conocido los mayores esfuerzos de la P.A.C. se han destinado a la política de precios y mercados. Sin embargo, el problema de los excedentes y la necesidad de reducirlos hizo que ya en 1960 se impulsará una política estructural que, inspirada en el Plan Mansholt —creación de explotaciones mayores y reducción del número de activos-, consiguió plasmarse en tres directivas aprobadas en la década de los setenta. Se trata de la Directiva 159/72 sobre Modernización de las explotaciones, la Directiva 160/77 de Cese de la actividad agraria y reasignación de la tierra agrícola a la mejora estructural y la Directiva 161/1972 de Orientación socioeconómica o profesional. Concretamente, ésta última pretendía compatibilizar las tareas agrarias con otras, como por ejemplo el turismo. A estas directivas se sumaron otras, entre la que destaca la Directiva 768/1975 sobre Agricultura de Montaña, y áreas desfavorecidas.

Habría que esperar, sin embargo, al año 1985 para encontrar los primeros reglamentos con contenidos serios sobre política de estructuras agrarias, cuando aparecen los Reglamentos (CEE) 797/1985 sobre Mejora de la Eficacia de las 
Estructuras Agrarias y el 2088/1985 sobre Programas Integrados Mediterráneos. Pero en estas fechas, la situación todavía estaba marcada por los mismos problemas de etapas precedentes, con el agravante de que los excedentes de mano de obra y producción no podían ser absorbidos ni por un panorama económico dominado por el paro, ni por un mercado condicionado por una demanda muy inferior a la oferta.

De ahí que el Reglamento (CEE) 797/1985, que en España fue desarrollado por el RD 808/87, además de recoger el contenido de las directivas anteriores incorpore, como novedad, los objetivos ecológicos y medioambientales, y los estímulos para interrumpir el éxodo rural mediante ayudas a la modernización de las explotaciones. Pero estas medidas no han sido suficientes para solucionar el problema de los excedentes, afrontar el elevado gasto monetario de la política de precios, la degradación del medio natural por los métodos intensivos de explotación, y el malestar en el ámbito de las relaciones con Terceros Países por el fuerte grado de protección de la política agraria comunitaria, objetivos éstos que exceden con mucho de los planteamientos que debieran haber presidido la aplicación de un Reglamento (CEE) más específico en la aplicación a estructuras agrarias que no a precios y mercados como, aparentemente, parece justificarse para su derogación.

En conexión con estas acciones se formula el Reglamento (CEE) 2328/1991 del Consejo de 15 de julio de 1991, que deroga al Reglamento 797/85 y con el cual se dice que van a acentuarse las acciones para la mejora de la eficacia de las estructuras agrarias, ya que en esos momentos se toma conciencia de que es la política de estructuras, la que ha de facilitarla adaptación de los agricultores a la nueva regulación de precios y mercados que, dada la disminución de la protección, producía un detrimento en las rentas agrarias.

Así pues, la política de estructuras, durante tantos años, se revela como la solución para contrarrestar estos efectos mediante la diversificación de las actividades productivas de las explotaciones, el refuerzo de los sistemas de producción y comercialización en coordinación con las tendencias de los mercados tanto interior como exterior y, asimismo, el mantenimiento de los ingresos de los agricultores.

En concreto, el Reglamento (CEE) 2328/91 establece un sistema de ayudas para la retirada de las tierras de cultivos herbáceos, extensificación de los métodos de producción, reconversión de la producción, inversión en explotaciones agrícolas, agricultura de montaña y zonas desfavorecidas, repoblación forestal y formación profesional. Por su parte el R.D. 1887/1991 que desarrolla la anterior normativa en el estado español prioriza las inversiones en Planes de Mejora, la incorporación de jóvenes agricultores, la introducción de la contabilidad, las agrupaciones de servicios, la repoblación forestal de zonas agrarias, la cualificación profesional, y la ayuda a zonas sensibles. 
Las diferencias entre los Reglamentos (CEE) 797/85 y 2328/91, y entre los dos Reales Decretos — 808/87 y 1887/91 - que regulan su aplicación en territorio español, son sustanciales. El RD 1887/91 concede unas ayudas mucho más modestas que de forma casi exclusiva se destinan a agricultores a título principal. También favorece la incorporación y primera instalación de agricultores jóvenes —entre 18 y 40 años—, y como novedad fundamental, además de las subvenciones de capital, se introduce una nueva fórmula de ayuda a la que cualquier agricultor muestra, por naturaleza, una elevada reticencia, esto es, los préstamos de capital bonificados concertados con entidades crediticias, lo que ha provocado que haya descendido notablemente - dos tercios menos- el número de solicitudes de ayuda en la Cuenca del Vinalopó, respecto de años anteriores.

Tampoco se puede ignorar, al respecto de este cambio de rumbo de la Política de Estructuras (CEE), que sus implicaciones sobre agriculturas como las existentes en el Vinalopó, o en otras comarcas valencianas o de la vecina región de Murcia, van a ser decisivas, no tanto por su utilización como por lo contrario. En efecto, y tomando como ejemplo la actual estructura de explotaciones agrarias que predomina en el Vinalopó, se comprueba que el número de potenciales peticionarios de esas ayudas (CEE) - los agricultores a tiempo completo y los jóvenes agricultoresconstituyen una auténtica minoría en relación al amplio segmento de explotaciones dirigidas por agricultores a tiempo parcial, a los que se cercena totalmente la posibilidad de accederá las ayudas establecidas en el RD 1887/91.

\subsection{Balance de las ayudas económicas recibidas en la Cuenca del Vinalopó a través del RD 808/87 durante el trienio 1989-1991}

El haber analizado uno por uno todos los expedientes de solicitud de ayuda del RD 808/87 ha permitido accederá una fuente de documentación de indudable valor y novedad. Con la declaración de Objetivo 1 para la Comunidad Valenciana se está en disposición de acceder a las ayudas concedidas por los fondos comunitarios estructurales: FEDER, FSE, y en particular el Fondo Europeo de Orientación y Garantía Agraria (FEOGA-Orientación), que establece como uno de sus objetivos prioritarios, la promoción de la acción común para la eficacia de las explotaciones y contribuirá la evolución de las estructuras.

Dicha finalidad es desarrollada por el Reglamento (CEE) 797/85, y adaptado al caso español con el RD 808/87 (BOE nº 26, de junio de 1987; $\mathrm{BOE} \mathrm{n}^{\circ} 239$, de 5 de octubre de 1988) que considera entre sus posibles beneficiarios tanto a explotaciones individuales como asociativas, siempre y cuando se cumplan unos requisitos básicos que sucintamente vienen a significar:

- estar adscrito a la categoría profesional de agricultura título principal (dedicación a la explotación en más de un 50\% de su tiempo laboral y con el añadido de que las rentas agrarias deben suponer al menos, el $50 \%$ de sus rentas totales.) De 
no ser así, los agricultores a tiempo parcial verán disminuidas las ayudas percibidas en un $10 \%$ de las máximas establecidas.

- compromiso de adoptar una contabilidad simplificada de la explotación durante 5 años, aunque las zonas desfavorecidas y de montaña del estado español como la Cuenca del Vinalopó se ven eximidas, por el momento, de esta medida.

- presentar un plan de mejora de la explotación, para lo cual se consideran como objetivos prioritarios la mejora cualitativa y adaptación de la producción a los mercados, la reducción de costes de producción, y el ahorro de agua, entre otros.

- otro de los requisitos exigidos es que la renta por unidad trabajo-hombre de la explotación ha de ser menor que una renta de referencia, que en el año 1990 fue de 1.868 .000 pesetas.

La cuantía de las ayudas se establecía mediante un complejo baremo de todas las inversiones previstas; así, para bienes inmuebles y mejoras permanentes podía alcanzar — año 1989 - hasta un $50 \%$ a fondo perdido, y para el resto de inversiones hasta un $40 \%$ de la inversión. Además de favorecer la introducción de mejoras en explotaciones agrarias dirigidas por todo tipo de peticionarios - menores ayudas a los agricultores a tiempo parcial—, esta política de estructuras comunitaria intenta estimular, mediante una línea específica de ayudas, la introducción de agricultores jóvenes - los menores de 40 años de edad- a través de unas primas únicas — alrededor de un millón de pesetas - y de la bonificación de intereses de los préstamos solicitados; si también presentaban un Plan de Mejora de la explotación, la ayuda podía ascender — el Vinalopó es una zona Desfavorecida- a un $62,5 \%$ de la inversión prevista.

De cualquier forma, si se considera la tendencia seguida por el número de expedientes de solicitud de ayuda del RD 808/87 emitidos en el trienio 1989-1991 desde toda la provincia de Alicante, y en particular desde las tres comarcas del Vinalopó, se comprueba que dicho número ha ido decreciendo de manera sucesiva en los tres años citados, de los 552 expedientes aprobados en 1989 - 148 eran del Vinalopó- a los 72 de 1991 -37 de éstos eran del Vinalopó-, si bien, cabe indicar que en este último año el procedimiento de derogación del RD 808/87 y sus sustitución por el RD 1887/91 fue tan mal llevado que de las 417 solicitudes demandadas desde toda la provincia tan sólo fueron aprobadas 72 .

Las diferencias en la infraestructura ecológica que median entre las tres comarcas del Vinalopó, los expedientes de solicitud de ayuda del RD 808/87 revelan la existencia de unos distingos importantes entre dichas comarcas. Empero, también se pueden establecer algunos denominadores comunes a todas ellas, sobre todo, aquéllos que se relacionan con la realización de Planes de Mejora sobre los sistemas de manejo del agua para riego, esto es, riegos de alta frecuencia y balsas de riego. 
2.1.1. Tendencias recientes de las estructuras agrarias en el Alto Vinalopó: aumento de la intensidad de explotación en cultivos hortofrutículas y en tradicionales

Las estrategias de actuación que traducen los 32 expedientes de solicitud de ayuda del RD 808/87 consultados, confirman que los agricultores del Alto Vinalopó han optado por aumentarla eficacia económica de sus explotaciones agrarias pero sin introducir variaciones productivas importantes, de forma que durante el trienio 1989-1991 analizado, ha sido muy usual la introducción de riegos localizados no sólo en cultivos frutícolas ya tradicionales - manzano, prunáceas y cerezo- sino también en olivo, o en cereales — con riegos por aspersión-. Escapa a esa tendencia la introducción de algunas especies hortícolas en regadío intensivo - mediante equipos de aspersión-, entre las que destaca la zanahoria, debidas en parte al mimetismo que han inducido las actuaciones en el municipio de Villena de grandes empresas agroalimentarias como Frudesa, Orfre, y Emilio Micó, y a la herencia de la especialización hortícola que todavía se conserva en algunos pequeños enclaves de la Huerta y de La Laguna. Por ello, existe un claro nexo de unión entre todas las mejoras citadas, es decir, se instalan unas 222 has riegos de alta frecuencia - unas 100 has en Villena- en las modalidades de goteo, microaspersión, y aspersión, tanto en nuevas como en viejas plantaciones — hasta en olivo-, a precios de instalación que oscilan — según diseño— de las 760.000 pts/ha en goteo, a las 400.000 pts/ha en riego por aspersión, que puede ser tanto móvil montado sobre trineos como en equipo fijo.

Que los riegos localizados ocupen un lugar destacado en los objetos de inversión de los expedientes del RD 808/87 del Alto Vinalopó no ha de extrañar en modo alguno, si esas decisiones se apoyan en argumentos y razones de peso. El sistema acuífero de Jumilla-Villena, uno de los más importantes de la comarca y de toda la Cuenca del Vinalopó por el volumen de gasto realizado, fue declarado sobreexplotado en 1987, como también podrían haberlo sido otros de la comarca, lo que traduce costes del agua para riego que, aunque mucho más baratos —alrededor de las $8 \mathrm{ptas} / \mathrm{m}^{3}$ - que los del Medio Vinalopó, ya exigen medidas de ahorro serias que parecen reservadas a los riegos de alta frecuencia.

Asimismo, como sistemas de manejo del agua para riego y como nuevos sistemas de explotación agraria permiten aumentar la intensidad de explotación y la rentabilidad económica obtenida de la misma; de facto, en todos los cultivos se experimentan sustanciales aumentos de rentabilidad económica que rayan en lo increíble si un mismo cultivo pasa de riego tradicional o por inundación a riego localizado; los incrementos más espectaculares corresponden a olivo —en Villena por ejemplo una hectárea de secano produce unos ingresos de 18.000 ptas. en secano y 105.000 en riego por goteo- y a cereal — de 46.176 ptas/ha en secano a 


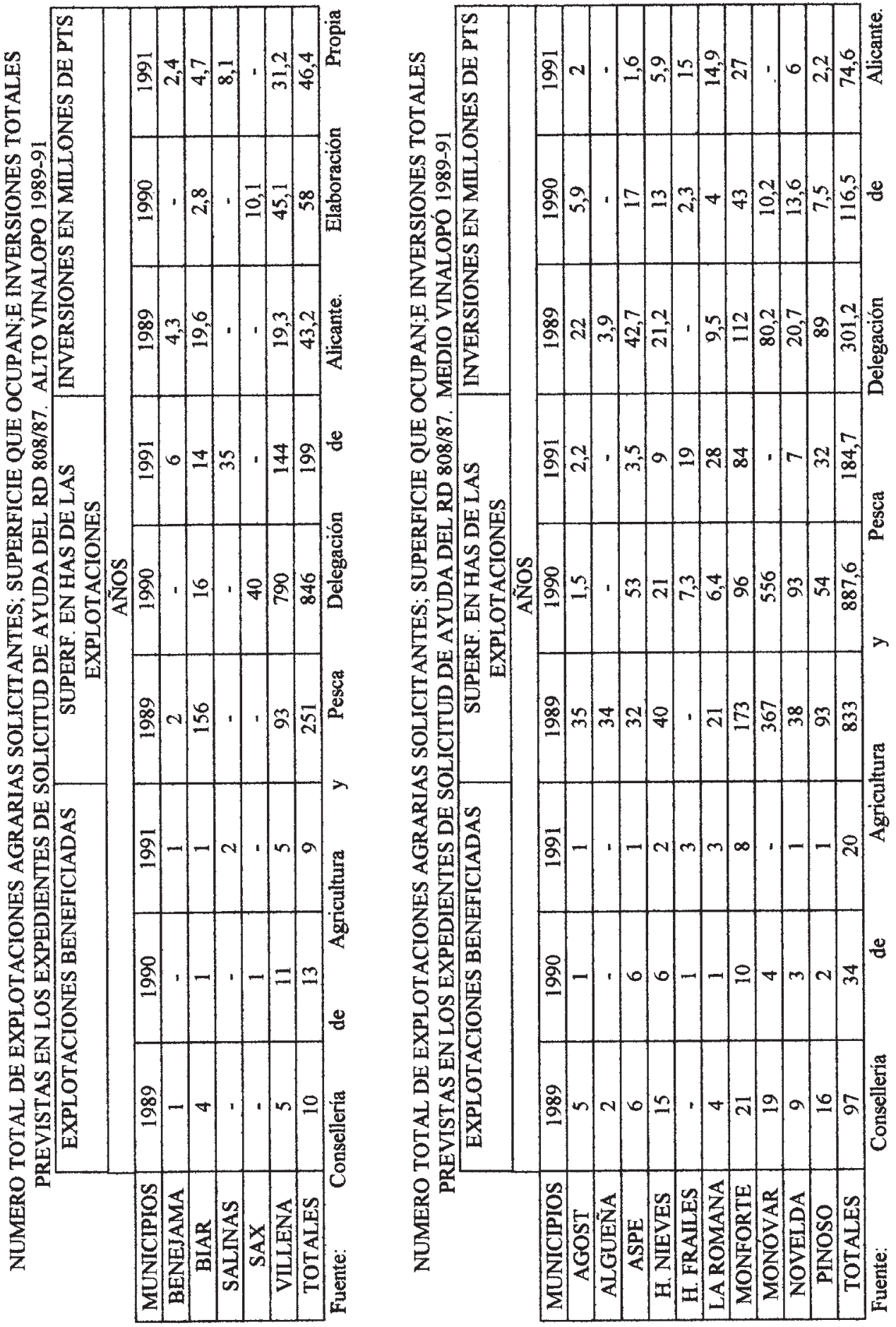


195.000 ptas/ha en riego por aspersión-, pero no son menos expresivos dichos aumentos en zanahoria —de 204.650 ptas/ha en riego tradicional a 269.700 en riego por aspersión - y en frutales como ciruelo, cerezo, o melocotón.

Aperos y maquinaria — tractores de más de $60 \mathrm{CV}$ —; bienes inmuebles — almacenes-; los ya citados costes de plantación — por ejemplo una hectárea de olivo asciende a unas $425.000 \mathrm{ptas} / \mathrm{ha}$-; o inversiones en el sector ganadero tales como la adquisición de una máquina de ordeño u ovejas de la raza segureña a 12.000 pesetas por unidad; completan el abanico de objetos de inversión más demandados por los peticionarios del Alto Vinalopó a la hora de justificar un Plan de Mejora, que posibilite un aumento de la eficacia económica de la explotación beneficiada. En ese sentido, todos los peticionarios estiman a su juicio que la rentabilidad económica que obtienen en sus explotaciones agrarias va a mejorar sensiblemente; como promedios, no referidos a unidad de superficie o hectárea, en todos los municipios del Alto Vinalopó se verifican dichos aumentos de rentabilidad que son menores en el municipio de Benejama — con 9 has en regadío y 1 ha en secano de promedio de base territorial por unidad de explotación-, pues dicha rentabilidad se eleva de 2.140 .000 ptas. a 2.900 .000 ptas.

En el resto de municipios del Alto Vinalopó, con un número mayor de solicitudes que puede ser más representativo de la realidad, los aumentos de la mano de obra empleada en la explotación son generalizables a todos los segmentos considerados - empresarial, familiar, y asalariada - por lo que se puede aducir que, al menos en estos municipios y en las otras dos comarcas del Vinalopó, toda innovación agrotécnica viene seguida asimismo por una intensificación en los recursos de trabajo que necesita la explotación mejorada.

Si se analiza la estructura de tamaño de las explotaciones agrarias del Alto Vinalopó acogidas al régimen de ayudas del RD 808/87 durante el período 19891991, se comprueba que en municipios como Villena — con 21 solicitudes - o Biar — con 6-, a la postre los que más demandan dicha línea de ayudas de los Fondos Estructurales de Orientación y Garantía Agraria, las explotaciones mayores de 10 has suponen — en cualquier caso — más del $80 \%$ de todas las peticionarias. Más expresivo es el porcentaje de Villena, ya que el segmento de explotaciones que exceden de 25 has —alguna de ellas supera las 300 has — que se acogen al RD 808/87 supera el $61 \%$ del total.

Se consolida, por tanto, una situación que se repetirá en las comarcas del curso medio y bajo del Vinalopó marcada por el elevado tamaño medio de las explotaciones agrarias que solicitan las ayudas del RD 807/87, hecho éste que, como es ya sabido, devala por entero de la estructura de explotaciones que predomina en todo el ámbito del espacio subregional del Vinalopó, donde el segmento de explotaciones más amplio es el que se sitúa por debajo del umbral de cinco hectáreas, y dentro de éste, del segmento de menos de 2 has de extensión territorial.

Al menos en este aspecto, sí que parece existir una coincidencia entre los 
resultados de esta política de estructuras y los objetivos de unas autoridades administrativas que todavía piensan que el futuro de la agricultura española pasa obligatoriamente por el hecho de potenciar un segmento de explotaciones agrarias — denominadas prioritarias - de elevado o medio rango territorial, de marcado carácter familiar, y con agricultores jóvenes. En el Alto Vinalopó, los agricultores de plena dedicación han sido los titulares de explotación que más han demandado las ayudas del RD 808/87, en términos relativos que oscilan del $50 \%$ de Benejama —en realidad uno - al $85 \%$ de Biar; casi todos ellos — tan sólo Villena presenta un $15 \%$ de titulares que no lo solicitaron- han pedido ayudas económicas para acometer Planes de Mejora, pero también hay algunos —un $20 \%$ en Sax y un 84,6 \% en Villena- que solicitaron las Primas de Primera Instalación de Agricultores Jóvenes.

Y ya por último, indicar que las repercusiones de esta línea específica de ayudas (CEE) en la comarca del Alto Vinalopó no han sido, pese a las atractivas condiciones del RD 808/87, tan importantes como se esperaba; tan sólo 32 titulares de explotación optaron por solicitarlas durante el trienio 1989-1991, y de ellos — ver cuadro siguiente-, el $85 \%$ —unas 27 explotaciones- los son de los municipios de Villena y Biar.

Los 147,6 millones de inversiones realizadas en la comarca, de ellas un $40 \%$ aproximadamente son ayudas a fondo perdido, fueron aplicadas en un conjunto de 32 explotaciones cuya superficie territorial se elevaba a 1.296 has, si bien, es preciso aclarar que cuando un titular acomete un Plan de Mejora con su correspondiente inversión, en el expediente de solicitud se especifica la situación y extensión de la parcela de explotación afectada por la mejora, de forma que como sucede en un caso de Villena la inversión —introducción de goteo - se aplicaba a una parcela de 10 has, que estaba adscrita a una explotación de 102 has de las que 90 eran de secano.

Este comportamiento, que es generalizable sólo en parte a las otras dos comarcas, permite extraer una nueva consideración al respecto de estas ayudas, que puede matizara otra realizada con anterioridad; el aumento de la eficacia económica de las explotaciones beneficiadas no se realiza casi nunca con el aumento de la superficie de explotación; sí en cambio, es muy frecuente, en particular en esta comarca, que parcelas de secano pasen a regadío con técnicas de riegos de alta frecuencia, o que parcelas ya en regadío vean acrecentada la intensidad de explotación con esas mismas técnicas de riego, o con la sustitución de cultivos.

\subsubsection{Riegos localizados y crisis agraria en el Medio Vinalopó: la uva de mesa embolsada una especialización agraria consolidada}

Si se exceptúan los ya señalados municipios de Monóvar, Pinoso, y la Algueña en última instancia, cuya configuración territorial y agraria guarda más afinidad 
con los municipios del Alto Vinalopó y con la de algunos municipios murcianos aledaños como Jumilla o Yecla, el resto de municipios insertos en el Medio Vinalopó — los del Sector Central— presentan unas estructuras agrarias con un denominador común — la uva de mesa embolsada - y unas inercias agrotecnológicas bien definidas; efectivamente, a través de los expedientes de solicitud de ayuda del RD 808/87, se demuestra que las mejoras destinadas al aumento de la eficacia de las estructuras agrarias en esta comarca siguen, pese a la crisis del sector, apostando por el monocultivo de uva de mesa embolsada, aunque no exclusivamente, pues también se pueden advertir otras mejoras que consisten en la introducción de frutales con goteo, hecho que puede interpretarse como «una huida hacia adelante» dado que la rentabilidad económica en esos cultivos no es tampoco nada elevada. En consecuencia, si a la profunda atonía que afecta al cultivo de uva de mesa embolsada, añadimos otros factores igual de disuasorios como los granizos de 1988 y las inundaciones de septiembre de 1989, o el prohibitivo precio del agua para riego, se entenderá de inmediato que el número de solicitantes de estas ayudas (CEE) y las inversiones que acometen, haya decrecido tan ostensiblemente en el trienio 1989-1991; de hecho, se han registrado pérdidas del $50 \%$ en el número de solicitudes que son generalizables a todos los municipios, incluso a aquéllos que en 1989 se mostraron especialmente dinámicos —con más de 15 expedientes aprobados-, es decir, Hondón de las Nieves, Monforte del Cid, Monóvar, y Pinoso - ver cuadro siguiente-.

Por otro lado, y sin dejar de reconocer que estas explotaciones son las más activas en la incorporación de innovaciones agrotécnicas, tampoco se ha de obviar que constituyen un pequeño corpúsculo — siquiera un $2 \%$ - de las más de 8.000 explotaciones que existen en la comarca, de ahí, que el balance de estas ayudas haya de ser valorado con criterios no sólo cuantitativos sino también cualitativos, acerca de las estrategias que aplican algunos titulares de explotación para aumentar su eficacia económica.

El Medio Vinalopó no es, en modo alguno, una excepción de la norma ya comprobada en el Alto Vinalopó sobre la estructura de tamaño que predomina entre las explotaciones agrarias que se acogen a este régimen de ayudas (CEE); se repite de nuevo una estructura de tamaño muy peculiar en la mayoría de municipios, marcada por el exclusivo predominio de explotaciones de mediano y gran tamaño, atendiendo a los resultados económicos que se obtienen en los distintos umbrales de tamaño considerados.

En cuanto al perfil socioprofesional de los peticionarios, lo usual es que se trate de explotaciones individuales, tanto de agricultores a título principal como de agricultores a tiempo parcial, aunque también se dan casos de solicitudes procedentes de explotaciones asociativas muy numerosas en el Municipio de Monforte del Cid, donde la dimensión comercial y productiva suelen concurrir en estas organizaciones. Esta política de estructuras ha resultado más atractiva para los 
agricultores profesionales en porcentajes que en cualquier caso no descienden del $50 \%$ de expedientes tramitados, oscilando del $50 \%$ de Hondón de las Nieves al 100 \% de La Romana y Hondón de los Frailes; curiosamente, entre el segmento de explotaciones de agricultores a tiempo parcial que acceden a esta línea de ayudas, son otra vez las de mayor tamaño las únicas que las solicitan —algunas superan las 50 has de tamaño-, hecho que evidencia que las ventajas de tamaño son decisivas a la hora de acometer un Plan de Mejora. De idéntica forma, entre los agricultores a título principal que solicitan las ayudas del RD 808/87, los más dinámicos son los titulares de explotaciones con un tamaño medio que ronda las 4 ó 5 has en el Sector Central del Medio Vinalopó, y las 20 ó 30 has en los regadíos y secanos interiores de los municipios de Monóvar y Pinoso — más afines al Alto Vinalopó-.

CLASIFICACIÓN POR CATEGORÍAS DIMENSIONALES DE LAS EXPLOTA-
CIONES ACOGIDAS AL RÉGIMEN DE AYUDAS (CEE)
ESTABLECIDAS EN EL RD 808/87. MEDIO VINALOPÓ 1989-91

\begin{tabular}{|lllll|}
\hline & \multicolumn{5}{c|}{ Intervalos en Has } \\
\cline { 2 - 5 } Municipios & de 0 a 2 & de 2 a 5 & de 5 a 10 & $>\mathbf{1 0}$ \\
\hline Agost & $33,3 \%$ & $0 \%$ & $33,3 \%$ & $33,3 \%$ \\
Aspe & $0 \%$ & $36,7 \%$ & $36 \%$ & $27,3 \%$ \\
Hondon Frailes & $0 \%$ & $33 \%$ & $67 \%$ & $0 \%$ \\
Hondon Nieves & $12,5 \%$ & $25 \%$ & $37,5 \%$ & $25 \%$ \\
La Romana & $0 \%$ & $25 \%$ & $75 \%$ & $0 \%$ \\
Monforte Cid & $4,16 \%$ & $45,83 \%$ & $25 \%$ & $25 \%$ \\
Monóvar & $0 \%$ & $0 \%$ & $13,3 \%$ & $86,7 \%$ \\
Novelda & $0 \%$ & $28,5 \%$ & $28,5 \%$ & $43 \%$ \\
Pinoso & $0 \%$ & $0 \%$ & $14,3 \%$ & $85,7 \%$ \\
\hline
\end{tabular}

Fuente: Conselleria de Agricultura y Pesca Delegación de Alicante. Elaboración Propia.

Por tipos de ayuda son otra vez los Planes de Mejora de la explotación los que despiertan un mayor interés entre los solicitantes, mientras que los auxilios económicos destinados a la introducción de la contabilidad en la explotación, o para la instalación de agricultores jóvenes, han tenido un éxito bastante menor. Baste indicar que en el trienio 1989-1991 el número de expedientes del Medio Vinalopó tramitados como ayudas a la primera instalación fue tan sólo de 12 - un $8 \%$ del total-; con ello se demuestra entonces que no son suficientes los estímulos económicos -Primas Únicas; bonificación de intereses; o subvenciones de capital 
a fondo perdido en los Planes de Mejora de un 62,5 \%- para reclutar unos agricultores jóvenes que aprovechan la más mínima ocasión para abandonar la explotación agraria. Estos titulares, además de solicitar la Prima de Primera Instalación casi siempre presentan un Plan de Mejora de la explotación — con un tamaño medio de 4 has- que van a dirigir, a la que acceden por compra, o mayormente a través de un contrato de arrendamiento con sus padres, a los que suceden en la dirección y gestión de la explotación, por hallarse éstos jubilados o próximos a esa situación ${ }^{1}$.

En el apartado de objetos de inversión solicitados por los peticionarios en los Planes de Mejora para aumentar la eficacia económica de la explotación se demuestra la importancia que reviste la escasez de agua para riego, y que los riegos de alta frecuencia se constituyan como la herramienta más utilizada por los solicitantes del RD 808/87 para optimizar y racionalizarlas estructuras productivas de sus unidades de explotación. No es por ello una casualidad, que en una comarca como el Medio Vinalopó donde se emplean electrobombas sumergidas de 1.000 C.V. de potencia para elevar 50 ó 60 1/s — con 2 ó $3 \mathrm{gr} / \mathrm{l}$ de sales disueltas- desde 600 metros de profundidad, las balsas de riego —unos $157.000 \mathrm{~m}^{3}$ - impermeabilizadas con Butilo o P.V.C. y los riegos de alta frecuencia, más concretamente la modalidad de riegos por goteo, aparezcan en todos y cada uno de los municipios de la comarca — excepto la Algueña — como los objetos de inversión más demandados.

La instalación de los riegos localizados, se realiza a costes medios que varían según los tamaños de la explotación y el diseño, de las 475.000 pesetas por hectárea — sin balsa - a las 915.000 ptas/ha si se construye además una balsa reguladora. Este sistema de manejo del agua para riego es empleado tanto en plantaciones en producción como en nuevas plantaciones, de forma que los peticionarios estiman aumentos muy sustanciales de rentabilidad económica, casi espectaculares, en todas las líneas de producción hortícolas y frutícolas existentes en la comarca.

Así por ejemplo, en el Sector Central, donde el dominio de la uva de mesa en formas apoyadas — en espaldera y pérgola — es aplastante — unas 11.000 has — se declaran rendimientos económicos en el sistema de riego tradicional que oscilan de $771.142 \mathrm{ptas} / \mathrm{ha}$ de Aspe, a 847.000 ptas/ha de Novelda —en uva de mesa aledo- En esos mismos municipios y con las mismas variedades, los solicitantes atribuyen al riego por goteo unas excelencias que en ocasiones se antojan, en relación a la realidad, desproporcionadas pues se atribuyen ahorros de agua del 25

1 El reducido número de solicitantes del RD 808/87 que solicitan las primas de primera instalación de agricultores jóvenes no es un fenómeno que se verifique únicamente en la Cuenca del Vinalopó. Así, en el resto de la provincia de Alicante ese número es también exiguo y, en cualquier caso muy inferior al número de solicitudes que se tramitan en la vecina provincia de Valencia, donde ese tipo de ayudas fue demandada en 1990 por el $37 \%$ de las 843 solicitudes totales que se tramitaron del RD 808/87, muy superior por tanto al $12 \%$ que ese mismo año fueron registradas en la Provincia de Alicante de un total de 520 expedientes. 
ó $30 \%$ en relación al sistema de riego tradicional. Con todo ello, se declaran rentabilidades económicas brutas en el sistema de riego localizado que varían de 980.000 ptas/ha de Hondón de las Nieves a 1.139 .000 ptas/ha de Novelda.

Otro de los objetos de inversión solicitados en el Sector Central del Medio Vinalopó consiste en la plantación de uva de mesa en formas apoyadas, con costes que rondan las $900.000 \mathrm{ptas} / \mathrm{ha}$ en espaldera y $1.300 .000 \mathrm{ptas} / \mathrm{ha}$ en pérgola. En este mismo capítulo de reordenaciones de cultivos, tendentes a mejorar la eficacia de la explotación, algunos titulares han pedido ayudas para plantar frutales con goteo, peral, melocotón y albaricoquero, en los municipios de Aspe, y los dos Hondones; y como anecdótico, pues no se hallan difundidos de forma significativa, cabe citar unas 6 has de palmeras e higueras con riego localizado en el municipio de La Romana, y unos $4.500 \mathrm{~m}^{2}$ de hortícolas — pimiento y tomatecon goteo y cubiertos bajo plástico en el seno de dos explotaciones familiares del municipio de Novelda.

Más al norte y hacia el oeste, en los municipios de Monóvar y Pinoso, sobre los glacis que tapizan las fosas tectónicas de Alciri-Mañá, Úbeda, y Pinoso, en las faldas meridionales del gran horst complejo de la Sierra de Salinas, se configura uno de los pocos sectores del Medio Vinalopó donde la creación de nuevos regadíos todavía ha superado en extensión, a la superficie desmantelada por efectos de la crisis que sufren los regadíos modernos. De esa forma, los cultivos de secano tradicional están más extendidos que en el Medio Vinalopó, con rendimientos que tienen tanto de variables según se trate de secanos o regadíos, como de escasos:

—así, la vid que en el municipio de Pinoso se suele regar por aspersión —unas $160.000 \mathrm{ptas} / \mathrm{ha}$ de rentabilidad bruta - duplica a los rendimientos de secano —unas 80.000—.

- este hecho que también se verifica en un cultivo muy venido a menos como el almendro —200.000 ptas/ha en regadío y apenas 65.000 en secano-.

Bajo estos planteamientos, la única posibilidad que se ofrece a los titulares de explotaciones agrarias de este sector del Medio Vinalopó, para elevar la eficacia económica y los rendimientos de sus explotaciones reside en introducir variedades eminentemente frutícolas que, por otro lado, cuentan con una ventaja ecológica —el mayor frío invernal—, y otra económica —agua de excelente calidad a unas 8 ptas $/ \mathrm{m}^{3}$ servida a presión por la Comunidad de Regantes de Pinoso y por la S.A.T. 5.914 «Juan Blanco» de Monóvar-. En ese escenario, se sitúan las nuevas plantaciones con sistemas de riego localizado de manzanos, ciruelo, peral, melocotón, y sobre todo, de cerezas — burlat y sumit — en los citados municipios de Monóvar y Pinoso, con productos económicos brutos que varían de 736.000 ptas/ ha en melocotón con goteo, a 1.150 .000 ptas/ha en cerezo.

Todas esas mejoras de la estructura productiva de las explotaciones agrarias del Medio Vinalopó acogidas a las ayudas (CEE) del RD 808/87 derivan, en correspondencia con la filosofía del reglamento (CEE) 797/85, en aumentos muy signi- 
ficativos de la eficacia económica de las explotaciones; con tamaños medios que, en general, son inferiores a los del Alto Vinalopó, los titulares de estas explotaciones agrarias declaran incrementos en los resultados económicos de la explotación agraria que por término medio elevan la renta bruta de trabajo obtenida, de 2.801.257 pesetas a 4.217.914 pesetas. Por otra parte, los solicitantes suelen declarar incrementos muy significativos de la mano de obra empleada —en jornadas/año- en la explotación que resultan mucho mayores en la empresarial y familiar prevista, si se trata de agricultores a título principal, o de la asalariada prevista - tras haber realizado el Plan de Mejora - en las explotaciones de agricultores con empleo principal en otras actividades económicas no agrarias.

\section{Balance de las ayudas (CEE) que priman el abandono definitivo de super- ficies de viñedo y de manzano en la cuenca del Vinalopó. 1989-1994}

Por la cantidad de explotaciones y superficie agraria afectada, esta línea de ayudas (CEE) merece un lugar destacado. Así sucede con los efectos de los Reglamentos (CEE) que regulan las primas por abandono definitivo de superficies de viñedo — n ${ }^{\circ} 1442 / 88$ y n $^{\circ} 2729 / 88$ - durante las campañas 1988/89 a 1995/96, y en menor medida con los Reglamentos (CEE) n $1200 / 90$ y n $^{\circ} 2604 / 90$ que regulan las ayudas destinadas a favorecer el abandono de superficies de manzano durante las campañas 1990/91 a 1992/93. Ahora bien, llama la atención que no se hayan ponderado los efectos que podrían provocar unas líneas de ayudas que favorecen el abandono de tierras de cultivo en un escenario como el Vinalopó que por una serie de limitaciones específicas, ya ha sido incluido en una declaración de Zona Desfavorecida. Mientras tanto, la extensión de tierras de cultivo que año tras año son abandonadas va creciendo de manera alarmante, muchas de ellas al amparo de estas ayudas (CEE), sobre todo las de viñedo, muy atractivas — quizás demasiado - que por su cuantía han acelerado un ajuste estructural que a nuestro juicio no es el más indicado, ni por la forma como se produce ni por sus efectos ${ }^{2}$.

2 En el citado Reglamento (CEE) 1442/88 sobre arranque definitivo de viñedo se prevé también que en determinadas zonas en las que concurran una serie de factores — ver también Reglamento (CEE) nº 1327/88 - podrá eximirse su aplicación.

En la Cuenca del Vinalopó todos esos factores concurren de sobras: pertenencia a una Denominación de Origen, hecho que se verifica no ya en una ocasión sino en dos Denominaciones de Origen como son «Alicante» para el vino, y «Uva de Mesa Embolsada del Vinalopó» en el caso de la uva de mesa; pluviometría anual inferior a $400 \mathrm{~mm}$ — hay estaciones por debajo incluso de los $300 \mathrm{~mm}$-; posibilidades muy limitadas de cultivos alternativos — más aún con lo escasa que está el agua para riego_-; riesgos de despoblamiento — esa situación ya se da en los valles interiores del Alto y Medio Vinalopó-; y, pese a todo ello, todos esos aspectos no se han considerado y se siguen arrancando viñedos, algunos de ellos de incalculable valor por su situación y por los costes sociales que entraña su desaparición. 
En lo que atañe a la aplicación de los Reglamentos CEE no $1442 / 88$ y 2729/88 que regulan las Primas por Abandono Definitivo del cultivo del viñedo, su cuantía ha variado en las distintas campañas de vigencia de los reglamentos, según se tratase de parcelas de uva de vinificación o parcelas de uva de mesa.

Así, mientras que una hectárea de uva de mesa en espaldera de las variedades aledo e italia se valoraba en 1988 en 5.268 ECU —unas 806.000 pesetas-, en 1992 era abandonada con una prima de $7.200 \mathrm{ECU}-1.101 .600$ ptas. - , mientras que ese mismo año el importe de la ayuda se elevaba a $10.800 \mathrm{ECU}$ por hectárea arrancada -1.652 .200 pts. - si el sistema de apoyo empleado era la pérgola. El importe de estas ayudas se reduce sensiblemente en parcelas de uva de vinificación, ya que la cuantía de la misma se establece previa clasificación de la plantación en unos segmentos de productividad en $\mathrm{Hl} / \mathrm{ha}$, que oscilaron en la campaña 1992/93 de 1.200 ECU/ha si la productividad era inferior a $20 \mathrm{Hl} / \mathrm{ha}$, a 10.200 ECU/ha si el vino producido era superior a $160 \mathrm{Hl} / \mathrm{ha}$; no obstante, la mayoría de explotaciones vitivinícolas del Vinalopó están mucho más cercanas al primer umbral de productividad que al segundo, de ahí que la cuantía de las ayudas sea bastante menor que en uva de mesa cultivada en formas apoyadas ${ }^{3}$.

Aunque el aceptar estas ayudas supone contraer una hipoteca de futuro - durante 20 años no se puede volverá plantar uva de mesa o vid en la parcela arrancada-, la crisis agraria de estos últimos años ha propiciado que numerosos agricultores se hayan visto atraídos por estas primas, al permitirles recuperar-siempre que cuenten con permiso de plantación si ésta se ha producido después de 1976- una pequeña parte de las inversiones que realizaron en su día.

\begin{tabular}{|cccc|}
\hline Campaña & $\begin{array}{c}\text { Uva de vinificac. } \\
\text { Has }\end{array}$ & $\begin{array}{c}\text { Uva de mesa } \\
\text { Has }\end{array}$ & $\begin{array}{c}\text { Total } \\
\text { Has }\end{array}$ \\
\hline $88 / 89$ & 335,3160 & 108,7475 & 444,0635 \\
$89 / 90$ & 970,5619 & 280,8600 & $1.251,4219$ \\
$90 / 91$ & 881,7121 & 237,1408 & $1.118,8529$ \\
$91 / 92$ & $1.177,6030$ & 486,8704 & $1.664,4734$ \\
$92 / 93$ & 968,5074 & 702,2394 & $1.670,7468$ \\
$93 / 94$ & 756,7492 & 343,7076 & $1.100,4568$ \\
\hline Total & $5.090,4496$ Has. & $2.159,5657$ Has. & $7.250,0153$ Has. \\
\hline
\end{tabular}

3 A este respecto hay un hecho que tiene mucha más importancia de la que parece, ya que los tipos de cambio del ECU — Unidad Europea de Cuenta - son decisivos para fijaren pesetas los importes de éstas y otras ayudas de la Comunidad Económica Europea. En estos casos se ha empleado el tipo de cambio existente en 1992 — unas de 153 ptas por ECU— pero en — julio de 1993 - con las sucesivas devaluaciones de la peseta, el tipo de cambio del ECU Verde estaba fijado en 182 pesetas, circunstancia que eleva todavía más el importe de todas las ayudas económicas procedentes de Bruselas. 
En general, todos los municipios analizados han experimentado tendencias crecientes en cuanto al número de solicitudes aceptadas y superficie arrancada se refiere; para analizarlas repercusiones territoriales de estos reglamentos (CEE) se ha creído oportuno distinguir entre dos sectores de producción bien definidos:

-En el Sector Central del Medio Vinalopó, donde el predominio de la uva de mesa en formas apoyadas es casi exclusivo, se han arrancado más de 1.500 has hasta la campaña 1993/94.

- y el resto de municipios del Vinalopó, donde las variedades de vitis que predominan son la monastrell, tintorera, valencós, manchegas, entre otras, que como es sabido se destinan a la elaboración de vinos se han arrancado más de 3.500 has en el mismo período.

Pero es de advertir, que esa distinción no permite evaluar — pues también los hay - arranques - poco significativos - de uva de mesa en municipios insertos en el grupo «uva de vino» como Monóvar o Pinoso, o viceversa, arranques de variedades viníferas en municipios del Sector Central como La Romana, Hondón de los Frailes, u Hondón de las Nieves incluidos en el grupo de «uva de mesa».

De todas maneras, y aunque la valoración territorial no varíe, el interés de esos distingos radica en ponderar en qué medida afectan los arranques de viñedo a un sistema de producción más intensivo como el de uva de mesa embolsada, o a un sistema más extensivo — casi siempre en secano — como el de la vid. Y asimismo, en cuantificar unas ayudas que por término medio rondan las 500.000 ptas/ha en los municipios de «uva de vino» y 1.100 .000 ptas/ha en los municipios del Sector Central del Medio Vinalopó especializados en uva de mesa.

En este último sector, «la uva de mesa embolsada del Vinalopó», pese a ser la única uva de mesa del mundo con denominación de origen, experimenta un franco retroceso, unas 1.547 has abandonadas — no son todas las que realmente se han abandonado-, que responden a las demandas de unos solicitantes que han optado por abandonar definitivamente la explotación agraria o una parte de ella, aunque lo cierto es que quien solicita estas ayudas suele hacerlo para todas sus parcelas de explotación. Además, para comprobar la magnitud del ajuste estructural que están desencadenando estas ayudas no basta con observar el ritmo desbocado que han seguido solicitudes y superficie arrancada en los cinco años de vigencia, hace falta también expresar su significación geográfica con criterios comparativos. En efecto, la superficie de uva de mesa arrancada con ayudas (CEE) supone más de un $18 \%$ de la extensión total que ocupa la uva de mesa en el Medio Vinalopó, con valores que son particularmente importantes en los municipios de Aspe, Monforte del Cid, y Novelda, pero también en los demás municipios si se considera que su potencial productivo es, en comparación con los anteriores, bastante menor. Suelen ser explotaciones de todo tipo las que se abandonan, aunque son más frecuentes las grandes explotaciones, cuya participación eleva de forma notable el tamaño medio — unas 3 has — de arranque por solicitud tramitada; de facto, estas ayudas 
son un último asidero empleado por sus titulares para evitarla ruina total, más aún cuando su cuantía está muy próxima al valor de una tierra que nadie quiere adquirir ni siquiera arrendar.

En uva de vinificación destacan los municipios de Monóvar, Villena, Pinoso, Salinas, y Sax, superan o se aproximan a las 500 has la superficie abandonada en los cinco mismos años se eleva a unas 4.000 has, esto es, un 25\% de la superficie total ocupada por la vid en el Vinalopó ha sido arrancada. Los solicitantes de estas ayudas han optado por los abandonos de unas explotaciones agrarias que al igual que en la uva de mesa han visto congelada o recortada la rentabilidad económica obtenida, hecho que no ha de extrañar si se tiene en cuenta que un buen vino tinto con Denominación de Origen Alicante puede adquirirse hoy, igual que hace cinco años, al módico precio de 75 ptas/litro.

Análoga importancia se debe otorgar a los Reglamentos (CEE) n ${ }^{\circ} 1200 / 90$ y $\mathrm{n}^{\mathrm{o}}$ 2604/90 que regulan las primas —unas $535.000 \mathrm{ptas} / \mathrm{ha}$ - por abandono definitivo del cultivo del manzano no destinado a sidra, durante las campañas 1990/91 a 1992/93. Pese a que sus repercusiones territoriales en la Cuenca del Vinalopó no han sido tan espectaculares como las de abandono definitivo de viñedo, entre otras razones porque este cultivo ya sufrió una crisis bastante importante a finales de la década de los años setenta que perdura todavía, y que determinó, sobre todo en el Alto Vinalopó, contracciones muy importantes de superficie cultivada. Hoy en día la situación no es mucho mejor, con unos mercados nacionales controlados por manzanas de Francia, Chile, Sudáfrica, o Nueva Zelanda, y con ayudas como la presente se ha logrado vencer, como era de esperar, la resistencia de unos 39 solicitantes que han accedido a ellas para arrancar unas 112 has de plantaciones, a menudo - como sus propietarios - con una edad avanzada, que han supuesto la retirada de la producción de un $10 \%$ de la superficie total dedicada al cultivo del manzano en el Alto Vinalopó — tan sólo Monóvar no se adscribe a dicha comarca- con especial mención al municipio de Villena del que proceden más de la mitad de solicitudes y un $64 \%$ de la superficie afectada por las primas de arranque.

\section{La reestructuración del viñedo en el marco de operaciones colectivas en la cuenca del Vinalopó. Reglamentos (CEE) no 3827/85 y n⿳2 2741/894}

Con una filosofía muy distinta a los reglamentos (CEE) que priman el arranque de viñedo, los reglamentos $(\mathrm{CEE}) \mathrm{n}^{\mathrm{o}} 3827 / 85$ y n $\mathrm{n}^{\mathrm{o}} 2741 / 89$ regulan las ayudas económicas tendentes a favorecerla plantación de superficies vitícolas, pero sin entraren contradicción con el reglamento (CEE) n ${ }^{\circ} 822 / 87$ que establece el funcionamiento de la Organización Común del Mercado Vitivinícola, ni con los reglamentos de arranque antes citados.

4 Se deben consultar también los Reglamentos (CEE) no 458/80, 2991/81, 1679/81, y 3397/81. 
En efecto, las ayudas que se concedan han de procurar no desviar de su objetivo inicial a los viticultores que tuvieran la intención de proceder a un abandono definitivo de superficies vitícolas, por lo que se insta a limitar el importe de esas ayudas a una parte de los costes reales de plantación, y a limitar las plantaciones a los mejores suelos vitícolas con variedades que mejoren la calidad y no tengan una elevada productividad, hecho que de producirse contraviene los objetivos de los reglamentos (CEE) de arranque de viñedo.

En esta ocasión se han analizado todas las ayudas concedidas —un total de 12 expedientes - para este fin concedidas a organizaciones u colectivos de productores organizados en régimen cooperativo, esto es, un total de 8 bodegas cooperativas cuyos ámbitos territoriales quedan en mayor o menor medida insertos en el Vinalopós.

Las ayudas concedidas se van librando conforme se verifican y certifican las operaciones estipuladas en los citados proyectos: arranque -45.000 ptas/ha—; desfonde y preparación del suelo — 110.000 ptas/ha—; desinfección del suelo con fitofármacos —unas $157.000 \mathrm{ptas} / \mathrm{ha}$-; abonado de fondo — $100.000 \mathrm{ptas} / \mathrm{ha}$-; adquisición de portainjertos y plantación — 197.000 ptas/ha—; labores del $1^{\circ}$ y $2^{\circ}$ año - 125.000 ptas/ha y año-; estas labores se planifican y efectúan en el marco de unos proyectos de reestructuración cuya duración ronda los seis años - la mayoría se iniciaron en 1987— y un importe de ayuda a fondo perdido que oscila, según municipios y fecha del proyecto, del $30 \%$ al $49 \%$ de la inversión total prevista.

No es nada habitual que el agricultor peticionario de estas ayudas de FEOGA solicite la reestructuración de todas sus parcelas de explotación plantadas de vid; lo más frecuente, si la edad del solicitante es avanzada, es que arranque una plantación vieja situada en un buen paraje a poder ser regable, la desfonde, y la mejore con nuevas variedades de vitis — abunda mucho la monastrell—, al tiempo que conserva otras parcelas de vid en cultivo, sin perjuicio de que más adelante las haya abandonado de forma definitiva con cargo a las atractivas ayudas del reglamento (CEE) $n^{\circ} 1442 / 88$. Otras veces, la reestructuración del viñedo es más profunda y completa; el titular aprovecha la ocasión para configurar, mediante un proceso de concentración parcelaria, parcelas de explotación de mayor tamaño, tal y como se puede comprobar en los expedientes presentados por las Bodegas Cooperativas «Campo San Blas» de Sax, y «Nuestra Señora de las Virtudes» de Villena; en la primera de ellas, los 72 cooperativistas peticionarios pretenden reestructurar una superficie de 567 has plantadas de vid, distribuidas en 238

5 La mayoría de estas bodegas cooperativas, por su ubicación territorial limítrofe con la provincia de Murcia, tienen asociados con residencia y fincas sitas en municipios murcianos. Por ejemplo, la Bodega Cooperativa Virgen de la Salud de Hondón de los Frailes presentó un expediente de reestructuración de viñedo que afectaba a 36 asociados y a 126 has repartidas por los municipios de Yecla, Abanilla, Orihuela, Hondón de las Nieves, y el propio Hondón de los Frailes. 
parcelas antes de acometer el proyecto —año 1990—, que más tarde, una vez completado se reducirán a 169 parcelas.

Las repercusiones estructurales de estas ayudas (CEE) son evidentes, como también lo son las territoriales y las económicas por la magnitud que adquieren; en efecto los 859 solicitantes de esas ayudas se benefician de 1.365 millones de pesetas a fondo perdido, destinados a subvencionar una buena parte - casi un $43 \%$ - de los 3.186 millones de pesetas en que se valoran todas las inversiones que requieren 3.752 has de viñedo para su reestructuración; de los planes presentados por las distintas bodegas cooperativas del Vinalopó, destacan — por su cuantía — los de Pinoso — 830 has_- Algueña — 792 has-, Campo San Blas de Sax -567 has—, y Ntra. Señora de las Virtudes de Villena -543 has-, al superar en todos esos casos el medio millar de hectáreas de superficie vitícola afectada por la reestructuración ${ }^{6}$.

\section{Otras ayudas (CEE) con repercusiones sobre las estructuras agrarias del Vinalopó por la vía de la protección de precios o de superficies de cultivo}

El abanico de líneas de ayuda a las que pueden acceder directamente los titulares de explotaciones agrarias a título individual de la Cuenca del Vinalopó, aunque sean las más importantes, no se agota en el RD 808/87, y en los distintos reglamentos (CEE) de arranque o reestructuración de viñedo ya evaluados. La adhesión de España a la Comunidad Económica Europea permite también que las explotaciones agrarias del Vinalopó puedan acceder a una serie de ayudas económicas —un $50 \%$ corresponde a FEOGA y el $50 \%$ restante al Ministerio de Agricultura y a la Conselleria de Agricultura - destinadas a favorecer la ordenación de cultivos y producciones agrícolas, de las cuales se han seleccionado aquéllas con una mayor importancia — por superficie y volumen de ayudas- en el Vinalopó.

En ese sentido cabe citar las ayudas a la producción de aceite de oliva - Reglamento (CEE) 136/66 - percibidas por unos 2.000 productores del Vinalopó en 1990, esto es, unos 54 millones de pesetas —un $30 \%$ del total provincial—, en una cuantía que varía según se trate de pequeños o grandes oleicultores - los que producen más de $400 \mathrm{~kg}$ anuales-; para los primeros, el importe de la ayuda se fijó en unas 53,8 pesetas por kilogramo de aceituna transformado en aceite, mientras que para los segundos ese importe decrece hasta fijarse en el mismo año en unas $40,5 \mathrm{ptas} / \mathrm{kg}^{7}$.

6 Los mayores tamaños medios — superficie/ $\mathrm{N}^{\circ}$ de solicitudes - corresponden de nuevo a los municipios del Alto Vinalopó; las bodegas cooperativas Campo San Blas de Sax y Nuestra Señora de las Virtudes de Villena con 7,8 has por solicitante son los mayores, aunque en general en todos los municipios se superan las 2 has de tamaño medio.

7 Conselleria de Agricultura: Memoria 1990, Generalitat Valenciana, 1991, pp. 84-85. 
El almendro, tanto de regadío como de secano, es otro de los cultivos representativos del Vinalopó que goza de la protección comunitaria - Reglamento (CEE) 2159/89 - por la vía de ayudas a planes de mejora de las explotaciones; estos planes, instaurados en la Comunidad Valenciana en 1990 pretenden favorecer la pervivencia de un tipo de aprovechamiento agrario que resulta vital en algunas de las zonas agrícolas más desfavorecidas de la comunidad, entre las que se cuenta el Vinalopó $^{8}$. El importe de estas subvenciones a fondo perdido es de 45.000 ptas/ha durante los primeros 5 años, y de 35.000 ptas/ha en los 5 años siguientes; por la forma en que se reparten dichas ayudas — a las Organizaciones de Productores-, es prácticamente imposible cuantificar y localizar sus repercusiones territoriales, puesto que en las dos Organizaciones de Productores de almendra más importantes del Vinalopó, esto es, la del Mañá en Monóvar, y la de Elche, hay un gran número de asociados cuyas tierras y domicilio está situado fuera del Vinalopó — hay incluso hasta de Granada-; no obstante, y contando con esa particularidad, estas ayudas se pueden valorar-en los dos años analizados: 1991 y 1992 - en unos 566 millones de pesetas que han beneficiado - lo más usual es comprar abonos o plaguicidas - a unas 12.600 hectáreas de almendro.

Como balance global final, cabe resaltar que estas líneas de ayuda destinadas a producciones y superficies agrícolas que se han evaluado no son todas las que hay, pero sí las más importantes. Existen otras que por diversas circunstancias - algunas, las incluidas en las Medidas de Acompañamiento General de la Reforma de la P.A.C., por su novedad - no se han podido evaluar, pero a las que los titulares de explotaciones agrarias del Alto y Medio Vinalopó también podrían acogerse, entre las que cabe destacar:

- Primas anuales, según lo dispuesto en el Reglamento (CEE) no 1359/93, por la cría de ganado ovino-caprino, con un importe que en zonas desfavorecidas como el Vinalopó puede oscilar de 27,7 ECU —unas 5.000 ptas.— por unidad de cordero pesado, a los 21,6 ECU — unas 4.000 ptas. por unidad - si se trata de corderos ligeros o hembras caprinas.

-Para la comarca del Alto Vinalopó reviste especial interés el sistema de ayudas a los productores de cultivos herbáceos — cereales, oleaginosas, y proteaginosas- en el marco de la Reforma de la P.A.C. que desarrollan los Reglamentos (CEE) $n^{\circ} 1765 / 92$ y no $1766 / 92$, y por el que se añade a los habituales precios de intervención una nueva fórmula generalizada de pagos compensatorios — cuantía unitaria por hectárea - tendente a mitigar la pérdida de rentas que supone el que los precios de intervención se reduzcan en futuras campañas.

Para esta misma comarca, también son aplicables las ayudas para el régimen de retirada temporal de tierras de cultivos herbáceos cuya finalidad es reducir los excedentes de esta Organización Común de Mercado pero sin primar el abandono

8 Conselleria de Agricultura: Memoria 1990, Generalitat Valenciana, 1991, p. 14. 


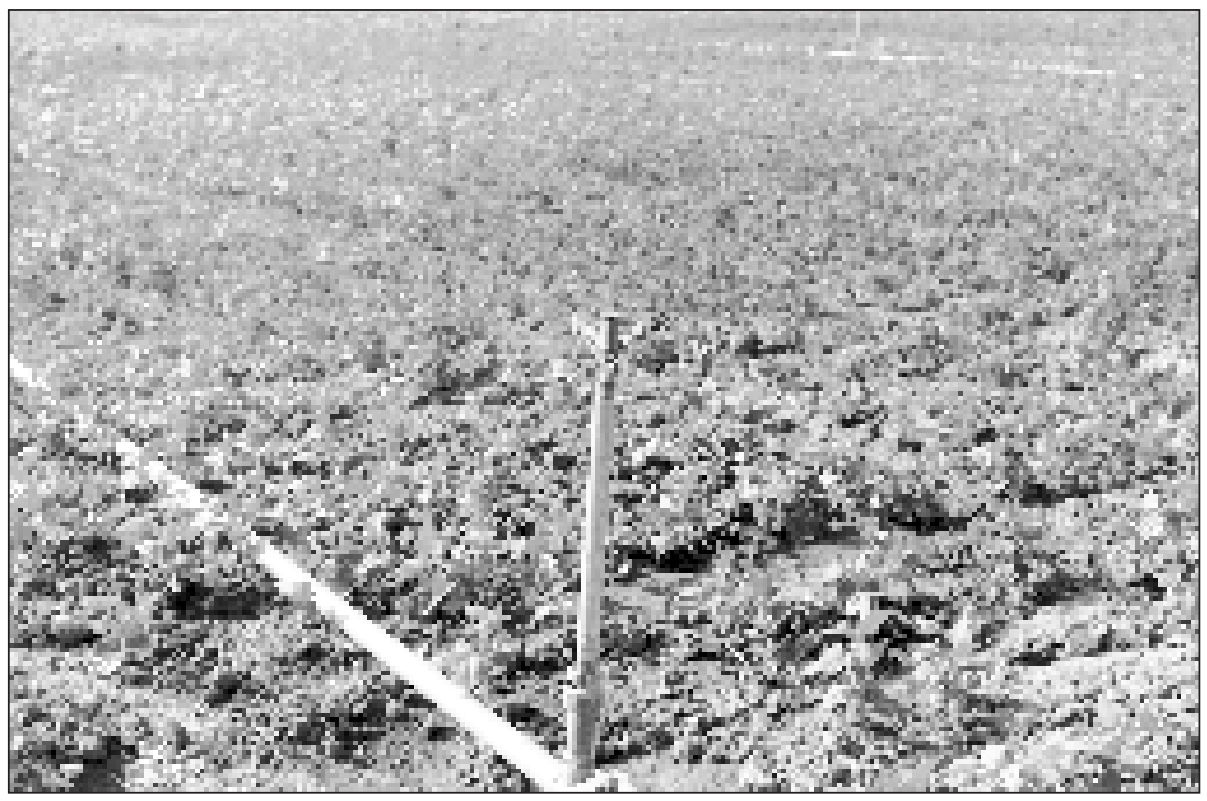

Fotografía $n^{o}$ 1. Aplicación de aspersión a hortalizas en el Alto Vinalopó. La mayor parte de explotaciones agrarias del Alto y Medio Vinalopó que han incorporado recientemente los sistemas de riego localizado lo han hecho con cargo a las ayudas del RD 808/87.

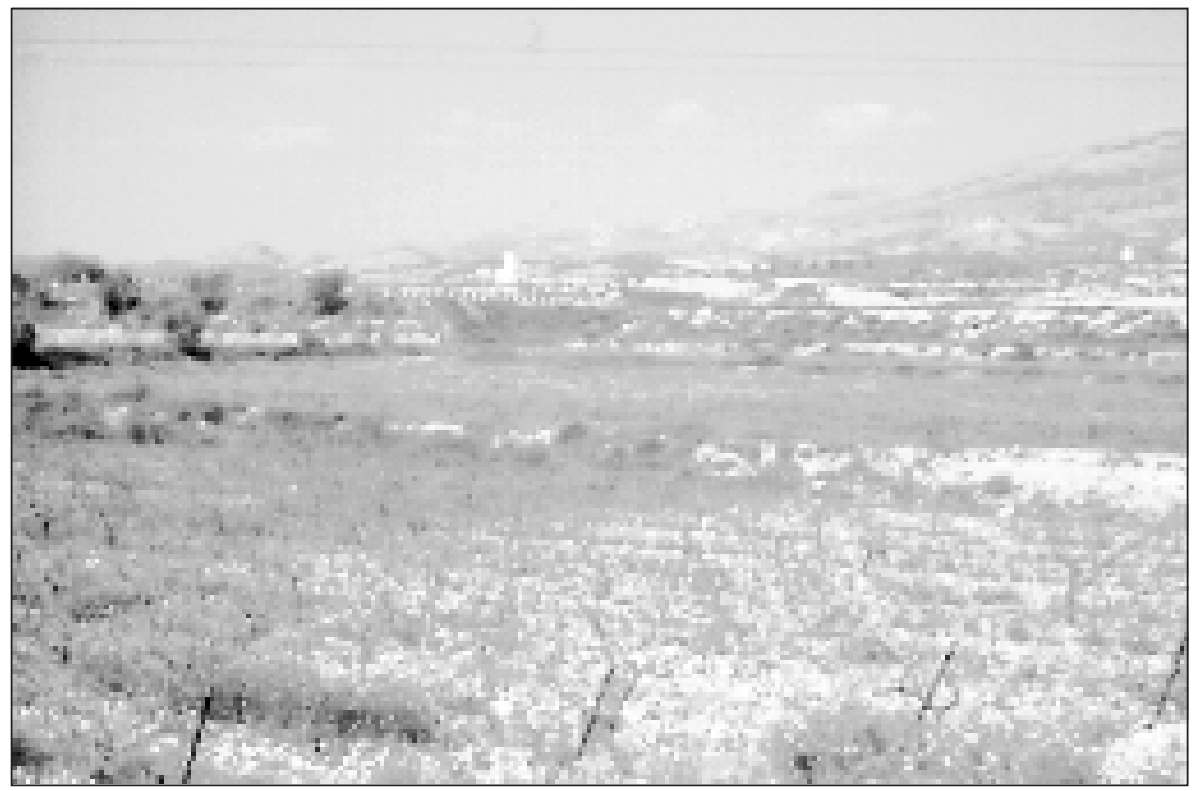

Fotografía $n^{\circ}$ 2. Parcelas de uva de mesa aledo abandonadas en Monforte del Cid. Más de 7.000 Has han sido abandonadas en el Vinalopó con cargo a las primas de la Unión Europea para abandono definitivo de superficies de viñedo. 
definitivo de las tierras, objetivo para el cual la CEE - Reglamento (CEE) 1703/91en cofinanciación con el SENPA, destina una ayuda de 11.401 pts/ha si se trata de una Zona Desfavorecida, y 13.197 ptas/ha de ser otra área.

También destacan las ayudas a la forestación de tierras agrarias durante el bienio 1993-1994 se ha demostrado que tal línea de ayudas no ha tenido la trascendencia que cabría esperara la vista de la mala situación en que se encuentran las explotaciones agrarias. En efecto, la cantidad de tierras agrarias abandonadas en el Vinalopó, y forestadas con cargo a estas ayudas ha sido tan sólo de 285 Has. solicitadas por 29 agricultores, a los que se ha concedido una ayuda total que se aproxima a 70 millones de pesetas.

\section{Alcance e implicaciones estructurales de la declaración de zona desfavore- cida por limitaciones específicas del Vinalopó. Directivas del Consejo 75/ 268/CEE, 466/86/CEE y 89/566/CEE}

De gran transcendencia en la aplicación de los fondos estructurales comunitarios en la Comunidad Valenciana y en el Vinalopó, ha sido su inclusión entre las regiones comunitarias menos desarrolladas o Regiones Objetivo $\mathrm{n}^{\mathrm{o}} 1$-Producto Interior Bruto per cápita inferior al $75 \%$ de la media comunitaria-; con esa declaración la Comunidad Valenciana está en disposición de acceder a la acción de los citados fondos a través de unos Programas Operativos que previamente exigieron la presentación por parte de la Generalitat Valenciana de un Plan de Desarrollo Regional, a partir del cual la CEE decidió un Marco Comunitario de Apoyo en el que FEOGA-Orientación se constituye como el fondo estructural y la fuente de financiación que de forma más directa incide en las estructuras agrarias.

La Política Agraria Común también prevé —Directiva del Consejo 75/268/ $\mathrm{CEE}$ - un régimen especial de ayudas económicas tendentes a aliviar y corregirlas desigualdades estructurales y naturales entre las distintas regiones agrícolas europeas. Para que una región agrícola se beneficie de ese régimen especial de ayudas deberá ser reconocido por el Consejo de la CEE, previa petición de los Estados miembros, como Zona Agrícola Desfavorecida - Directiva del Consejo 466/86/ CEE relativa a la lista comunitaria de Zonas Agrícolas Desfavorecidas-.

De las tres modalidades de Zonas Agrícolas Desfavorecidas posibles, es decir, de Montaña, por Despoblamiento, o por Limitaciones Específicas, es ésta última modalidad la esgrimida para conceder al Vinalopó tal condición.

En «La propuesta del Plan de Obras y Actuaciones en la Zona Desfavorecida por Limitaciones Específicas del Vinalopó (Alicante)», aprobado por orden de la Conselleria de Agricultura y Pesca de 7 de marzo de 1991, se justifica la declaración de Zona Desfavorecida del Vinalopó........en consideración a que constituye una comarca natural de gran importancia económica y social, donde la escasez de recursos hídricos suponen una gran limitación a sus desarrollo y una constante 
amenaza para su futuro. De ahí, la preocupación de las autoridades municipales — en realidad los ayuntamientos son los peticionarios de estas ayudas CEE- y autonómicas por paliar las enormes dificultades de suministro de agua para riego, por la sobreexplotación de acuíferos, que sufren las 30.000 has de cultivos intensivos de regadío que existen en la comarca, lo que explica el lugar destacado que ocupan las infraestructuras hidráulicas - conducciones de enlace y balsas de riego- en el Plan de Obras y Actuaciones correspondiente.

En efecto, estas ayudas a fondo perdido de FEOGA Sección Orientación cofinanciadas también por el Ministerio de Agricultura y por la Conselleria de Agricultura, tienen el objetivo prioritario de paliar unas limitaciones específicas de esta Zona Desfavorecida, esto es, la carencia de recursos hídricos, pero también se incluyen como inversiones de interés preferente la mejora —ampliación y asfaltado- de unos $181 \mathrm{~km}$ de viarios rurales por un importe de 1.448 millones de pesetas. Todas las obras previstas, a realizar en el plazo de 6 años contando a partir de 1990, traducen unas inversiones por un importe total que asciende a 4.563 millones de pesetas de los que un $70 \%$ corresponden al Medio Vinalopó, mientras que la inversión restante —unos 1.383 millones de pesetas — se destina a la realización de obras en el Alto Vinalopó.

La distribución municipal de las inversiones, su finalidad, y el coste que éstas representan demuestran que si se exceptúan los ya referidos $181 \mathrm{~km}$. de viarios rurales, 60 de los cuales radicarán en el municipio de Villena, el resto de inversiones —unos 3.115 millones de pesetas - se destinan a la realización, en algunos casos por la vía de urgencia, de infraestructura hidráulica. En este sentido se propone la construcción de una docena de embalses de agua para riego de gran capacidad —unos $3.830 .000 \mathrm{~m}^{3}$ - con un coste de 2.681 millones de pesetas, y la construcción de 62.000 metros de conducciones de enlace — de entrada a las balsas de riego y de conexión con las redes de riego- por un importe global de 434 millones de pesetas; descollan, por su capacidad, las balsas de riego impermeabilizadas de plástico que se prevé construir en Villena $-500.000 \mathrm{~m}^{3}$ para albergar aguas de la depuradora-; en Novelda $-500.000 \mathrm{~m}^{3}$ que reforzarán la capacidad de embalse de la S.A.T. Monteagud—; La Romana $-1 \mathrm{Hm}^{3}$ de aprovechamiento conjunto con Novelda en el pago de Algezares-; y Monforte del Cid $-1 \mathrm{Hm}^{3}$ en el paraje de la Majada de las Vacas-9.

El mayor interés de estas infraestructuras, al margen de la inestimable funcionalidad de las mismas, reside en que favorecen a todo tipo de explotaciones agrarias, destacando entre éstas, a aquéllas que por motivos de diversa índole

9 Sobre estas infraestructuras hay que indicar que no todas ellas se han realizado; algunas obras como los embalses de la Majada de las Vacas en Monforte, y el de Algezares en La Romana se han retrasado al no disponer de dotaciones presupuestarias para su realización, lo que denuncia una vez más, que la gestión de los fondos estructurales comunitarios no está resultando, por el momento, muy eficaz. 
- agricultores a tiempo parcial y titulares de pequeñas explotaciones- no pueden acceder a las ayudas del RD 1887/91. Al aumentar la capacidad de embalse de agua para riego, los entandamientos disminuyen su duración y aumenta la oportunidad del riego, además, estas infraestructuras básicas permiten actuar sobre la estructura de costes del agua subterránea, minimizando los costes de fluido eléctrico al alumbrar el agua en horas valle; las balsas permiten que sea almacenada y gastada a conveniencia.

\section{La ley de la Generalitat Valenciana 47/87 de 13 de abril de 1987 sobre la utilización del agua para riego.- Evaluación de las previsiones contenidas en el plan director de modernización de regadío de la comunidad valenciana}

Uno de los instrumentos de financiación con que podrían contar los agricultores del Vinalopó para afrontarlos elevados costes que supone la realización de obras de mejora en la infraestructura hidráulica es, sin duda, la Ley 47/87 de la Generalitat Valenciana sobre la Utilización del Agua para Riego. Sin embargo, no todos los agricultores pueden acceder a dichas ayudas económicas —un $40 \%$ de la inversión total se subvenciona a fondo perdido - puesto que si bien una mayoría de ellos se halla adscrito a alguna entidad de regantes, no todas esas entidades de regantes han adquirido todavía, tras 7 años de vigencia de la nueva Ley de Aguas de 2 de agosto de 1985, la condición jurídica de Comunidades de Regantes.

Las repercusiones económicas y territoriales de esta línea de ayudas aunque importantes, no alcanzan los valores de otra comarca alicantina también afectada por hondos problemas en el suministro de agua para riego como es la Vega Baja, donde se han realizado inversiones por un valor total de 5.436 millones de pesetas —un $72 \%$ del valor provincial— en infraestructura hidráulica durante el quinquenio 1988-1992.

En el Alto y Medio Vinalopó por la escasez de comunidades de regantes, tales inversiones, y por ende las ayudas recibidas, han tenido una cuantía bastante menor, que se explica también por la mala situación económica de unas explotaciones agrarias muy descapitalizadas que no pueden asumir el segmento de inversión —el 60 \% restante- no subvencionado. De hecho, en la Comunidad de Aguas de Novelda se sometió a votación entre sus comuneros si se procedía a una segunda petición de estas ayudas autonómicas para emprender una fase de ampliación de las conducciones de riego a presión ya construidas, posibilidad ésta que fue desestimada por una mayoría de la Junta de Aguas.

Si acaso, destacar que la comarca del Alto Vinalopó ocupa la segunda posición de la Provincia de Alicante si nos atenemos a la cuantía de inversiones que ha inducido la citada ley de utilización del agua para riego; además es de notar que en 1991 y 1992 las Comunidades de Regantes del Alto Vinalopó no presentaron ningún proyecto de solicitud de ayuda, mientras que las anteriores a dichos años 


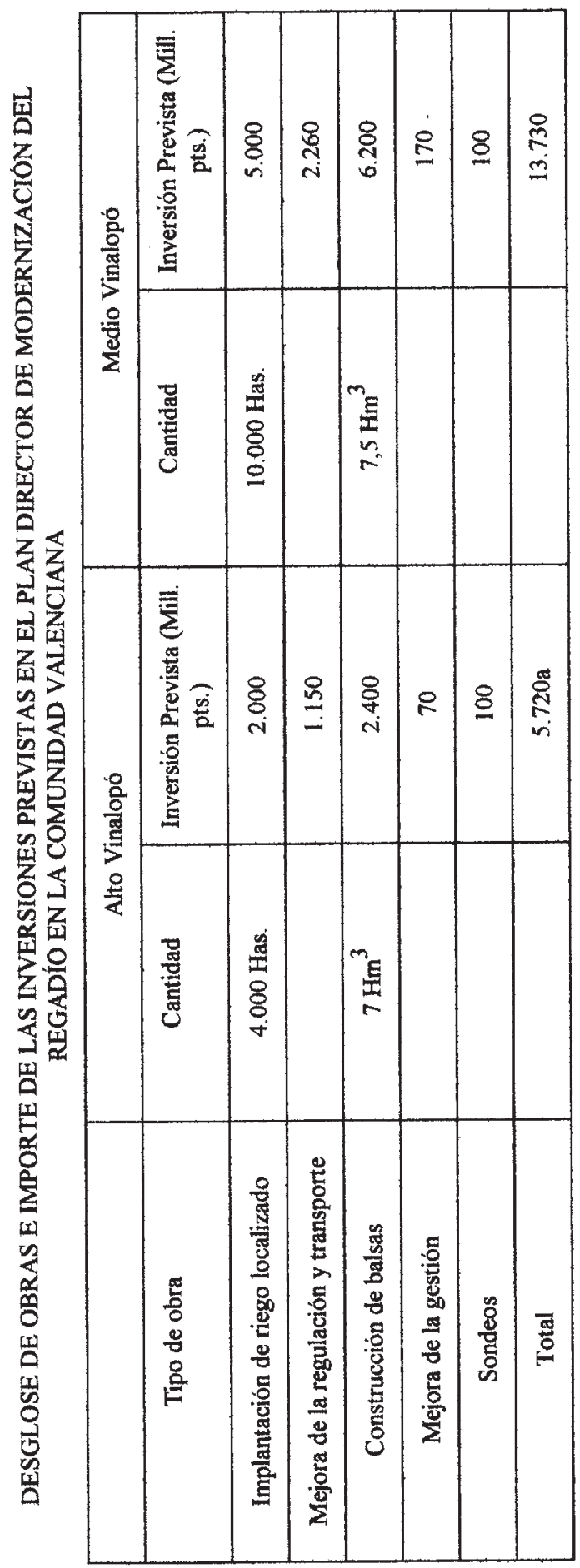


importaron unos recursos de capital a fondo perdido de 249.940 .000 ptas. sobre 624 millones de inversiones totales, es decir, el 8,28 \% de la inversiones realizadas en toda la Provincia de Alicante, durante el período 1988-1992.

En todas ellas, aunque no se especifique en las memorias que nos ha facilitado la Conselleria de Agricultura, las mejoras de las infraestructuras hidráulicas realizadas se incluyen dentro de ambiciosos planes de conversión del sistema tradicional de manejo del agua para riego al sistema de riego localizado, interesando a una superficie regable que supera las 3.000 hectáreas y a unos 1.500 usuarios agrarios, muchos de los cuales — una gran mayoría - no son agricultores a título principal.

El caso del Sindicato de Riego Público de la Villa de Sax puede ilustrar, por los espectaculares resultados alcanzados, la valiosa aportación que puede suponeruna línea de ayudas como ésta en la optimización de los sistemas de gestión del agua subterránea; con los dos planes de obras ejecutados en 1988 y 1990, y subvencionados a fondo perdido en un $40 \%$ de su importe total por la Conselleria de Agricultura, la Comunidad de Regantes de Sax ha logrado implantar en todo su ámbito territorial de actuación —unas 2.000 has — el riego a presión dirigido por un sofisticado sistema automático de información hidráulica con contadores volumétricos en cada parcela inscrita, lo que ha inducido asimismo una difusión muy notable de los riegos localizados de alta frecuencia ${ }^{10}$.

En el Medio Vinalopó, donde las dificultades que ocasiona la sobreexplotación de las aguas hipogeas son también importantes, en algunos casos hasta penosas, únicamente dos entidades de regantes han podido acceder a estas ayudas autonómicas, éstas son, la centenaria Comunidad de Aguas de Novelda y la Comunidad de Regantes de Pinoso ${ }^{11}$.

El importe de las ayudas a fondo perdido concedidas a estas dos entidades de regantes asciende a 153,7 millones de pesetas, lo que supone el $40 \%$ de un presupuesto total en inversiones cifrado en 384 millones de pesetas - tan sólo un $5,1 \%$ del total provincial- . Las repercusiones territoriales de estas subvenciones han sido importantes, pues en ambas se ha reconvertido una totalidad - caso de Pinoso - o una gran parte — caso de Novelda — de antiguos regadíos por inundación a riego a presión.

De esta forma, son muchos los titulares de explotaciones agrarias que al disponer de contadores volumétricos en todas sus parcelas —en Pinoso hay unos 3.000 contadores - han introducido riegos localizados, minimizando así unos costes de instalación que de otra manera, por la dispersión y pequeño tamaño de las parcelas,

10 Una parte importante de las inversiones realizadas en el Alto Vinalopó se han dedicado a la construcción de varios embalses de agua para riego con una capacidad de $469.000 \mathrm{~m}^{3}$.

11 La Comunidad de Regantes de Pinoso, integrada por las antiguas S.A.T. de Pinoso y de Ubeda, ha visto agilizada su conversión en una Corporación de Derecho Público al estar adscrita a la Confederación Hidrográfica del Segura. 
hubiesen resultado económicamente inasumibles por unas explotaciones agrarias muy descapitalizadas.

Como balance final a este apartado, parece razonable considerar que esta línea de ayudas autonómicas está llamada a adquirir un valor estratégico en la Cuenca del Vinalopó, si de una vez por todas se agiliza por parte del Organismo de Cuenca correspondiente la conversión de todas las entidades de regantes en Corporaciones de Derecho Público, es decir, en Comunidades de Regantes. Estas ayudas autonómicas pueden inducir un gran número de inversiones en infraestructura hidráulica que, sin duda, optimizarán los actuales sistemas de administración, gestión, y distribución de agua para riego; por otro lado, las obras que se acometan, al menos las que atañen a balsas de riego y a tuberías a presión, generarán economías de escala que abaratarán considerablemente los costes de instalación de nuevos sistemas de manejo del agua para riego y de explotación agraria más racionales como son los riegos localizados, cuya difusión ayudará en la evolución de las estructuras agrarias que todavía subsisten a la crisis agraria de estos últimos años.

En parte, continuando con la filosofía de este R.D., el Plan Director de Modernización del Regadío en la Comunidad Valenciana establece una serie de actuaciones que se ejecutarán en los próximos años con los objetivos prioritarios de regular los recursos naturales superficiales de la cuenca; la construcción de embalses de mediana capacidad para almacenar agua en horas valle; $y$, en tercer lugar, se hace especial hincapié en favorecer la implantación del riego localizado. (Vid cuadro siguiente).

\section{Conclusiones}

En general, la mayoría de las líneas de ayuda que se han analizado en este trabajo, desde el RD 808/87 relativo a la mejora de la eficacia de las estructuras agrarias, a las primas de abandono definitivo de viñedo, tienen un denominador común cual es el destino de las ayudas concedidas, es decir, la práctica totalidad de los beneficiarios son jefes de explotaciones agrarias a título individual. Si se exceptúan los efectos nada deseables de los reglamentos que regulan las primas por abandono definitivo de las superficies de viñedo, las ayudas administrativas comunitarias, estatales, y autonómicas, destinadas a explotaciones agrarias a título individual han tenido unas escasas implicaciones espaciales y estructurales, ya que han beneficiado a un reducido segmento de explotaciones agrarias, lo cual quiere decir que un número muy elevado de agricultores del Alto y Medio Vinalopó no han accedido, por diversas razones - tamaño, orientación productiva, perfil profesional del titular, o líneas de ayuda poco sugerentes- a las subvenciones de capital que se han evaluado anteriormente.

Por otro lado si la reciente reforma de la P.A.C. apuesta de forma definitiva por un modelo de agricultura europea donde dominen los agricultores profesionales, la 
evolución de las estructuras agrarias en espacios subregionales como el Vinalopó resultará muy compleja y nada halagueña. La razón es obvia, puesto que el fenómeno de la agricultura a tiempo parcial, bien como fuente de ingresos complementarios o bien como actividad lúdica, se halla muy difundida.

¿Qué alternativas de financiación y de evolución estructural se ofrecen a ese segmento de explotaciones agrarias tan numeroso en el Alto y Medio Vinalopó?

En última instancia, las únicas vías de financiación a las que pueden acceder todos los titulares de explotaciones agrarias, independientemente de su dedicación profesional, de los cultivos que practiquen, o del rango territorial que tengan, son aquellas ayudas administrativas CEE, estatales, y autonómicas, destinadas a la realización de infraestructuras agrarias de interés común y colectivo, bien en el seno de organizaciones de productores — almazaras y bodegas cooperativas- , de entidades de regantes, o en los ámbitos territoriales de los municipios beneficiados con esas ayudas. Por esta razón fundamental, si se quiere evitar que las llamadas Medidas de Acompañamiento de la Reforma de la P.A.C. como las ayudas para la forestación de tierras agrarias no tengan un excesivo éxito, sin duda nada deseable en una Zona Desfavorecida, se debe adoptar una política de estructuras agrarias que optimice todas la ventajas que ofrecen las líneas de ayuda destinadas a mejora de infraestructura agraria, renovación del tejido productivo, constitución de organizaciones de productores agrarios, adecuación de las estructuras de comercialización a la nueva realidad de los mercados europeos, entre otros aspectos, que tienen en la «Uva de Mesa Embolsada del Vinalopó» y en las líneas hortofrutícolas intensivas del Alto Vinalopó dos sectores productivos estratégicos de gran valor económico y social, donde quedaría plenamente justificada la aplicación de todas estas líneas de ayuda. 